\title{
DOCUMENTAÇÃO E ESTUDOS LEXICAIS SOBRE LIINGUAS INDÍGENAS
}

\author{
Mônica Veloso Borges \\ Núcleo Takinahakỹ de Formação Superior de \\ Professores Indígenas/Faculdade de Letras/UFG
}

\section{RESUMO}

Este texto apresenta alguns resultados do trabalho realizado no Curso de Educação Intercultural de Formação Superior de Professores Indígenas da Universidade Federal de Goiás, no estudo do Léxico, com alunos dos povos Tapirapé, Guajajara, Xerente, Xakriabá, Xavante, Gavião, Apinajé, Krahô, Krikati, Canela, Karajá, Karajá-Xambioá, Javaé e Tapuia, da Matriz Específica "Ciências da Linguagem”, dos anos de 2007 a 2013.

PALAVRAS-CHAVE: Estudo do Léxico. Curso de Educação Intercultural da UFG. Matriz Específica.

\section{ABSTRACT}

This paper presents some results of the Lexicon Study, in Intercultural Higher Education Course of the Federal University of Goiás, with indigenous teachers from the Tapirapé, Guajajara, Xerente, Xakriabá, Xavante, Gavião, Apinajé, Krahô, Krikati, Canela, Karajá, Karajá-Xambioá, Javaé and Tapuia people, from the Specific Matrix "Language Sciences", of the years 2007 to 2013.

KEYWORDS: The Lexicon Study. Intercultural Education Course of UFG. Specific Matrix.

Neste texto trarei alguns resultados obtidos no estudo do Léxico, no Curso de Educação Intercultural de Formação Superior de Professores Indígenas da Universidade Federal de Goiás. Esse trabalho foi realizado no Tema Contextual "Léxico: significados e relações sociais", ministrado por mim, para as turmas de alunos 
de 2007 a 2013, da Matriz Específica "Ciências da Linguagem", compostas por professores indígenas pertencentes aos povos Tapirapé e Guajajara (Tronco Tupi, Família Tupi-Guarani); Xerente, Xakriabá, Xavante, Gavião, Apinajé, Krahô, Krikati e Canela (Tronco MacroJê, Família Jê); Karajá, Javaé e Karajá Xambioá (Tronco Macro-Jê, Família Karajá); e Tapuia (falantes de língua portuguesa).

O referido Tema Contextual consiste no estudo do léxico das gerações mais antigas e dos espaços especializados, sagrados, cotidianos, masculinos e femininos, cujos objetivos são: (1) Discutir a noção de léxico e sua relação com visão de mundo; (2) Abordar as diferentes formas lexicais empregadas em espaços e relações sociais diversas, constatando e valorizando suas especificidades; (3) Analisar as relações formais, conceituais e pragmáticas existentes entre essas diferentes formas lexicais; e (4) Discutir metodologias de documentação lexical e de organização de dicionários para as línguas indígenas.

Serão apresentados aqui alguns resultados das discussões e dos trabalhos feitos pelos alunos sobre os seguintes temas abordados: (1) Léxico, seu contínuo processo de expansão e sua documentação; (2) Dicionários por campos lexicais ${ }^{1}$ escolhidos pelos alunos, tais como mitos, árvores, aves, peixes e artesanato; (3) Palavras antigas, em desuso, e palavras novas/criadas; (4) Empréstimos do português e formação de novas palavras nas línguas indígenas; (5) Palavras distintas entre idades/gerações e sexos; (6) Palavras distintas conforme as aldeias e regiões; e (7) Linguagem especializada e linguagem do cotidiano. O propósito deste texto é que essas reflexões possam contribuir com os professores indígenas em suas discussões e práticas pedagógicas referentes à documentação, ao estudo e ao ensino do léxico de suas línguas indígenas.

\section{LÉXICO: 'O ESTUDO DAS PALAVRAS'}

Dentre os temas trabalhados com todas as turmas, estão os que se seguem. As discussões incluíram conversas sobre aspectos

\footnotetext{
${ }^{1}$ Segundo Ilari (2002, p. 39), "Constituem um campo lexical as palavras que nomeiam um conjunto de experiências em algum sentido análogas. Os nomes das cores, por exemplo, que se referem a um tipo particular de experiência visual ou os nomes dos animais, que organizam parte de nossa experiência dos seres vivos, constituem campos lexicais."
} 
culturais e também sobre a estrutura e a formação de cada palavra apresentada.

a) Palavras antigas, em desuso:

- Xerente (Isaias Sizapi Xerente e Moisés Simnakru Pereira Xerente, da Turma de 2013):

\begin{tabular}{|l|l|}
\hline Srê & 'cofo sagrado' \\
\hline Saithu & 'simboliza o povo Xerente' \\
\hline Sbo & 'cofo de luto' \\
\hline Amzumkwasa & 'tempo' \\
\hline Wade & 'bajular' \\
\hline
\end{tabular}

b) Palavras antigas e palavras atuais:

- Karajá (Labé Kalariki Idjawaru Karajá, Lahyre Karajá, Moisés Waixa Karajá, Nelson Wanahuwa Karajá e Txiixe Iòló Tapirapé, da turma de 2013):

\begin{tabular}{|l|l|l|}
\hline Palavras Antigas & Palavras Atuais & Português \\
\hline Mrari & ralby, riòrelahi & Genro ou sogra \\
\hline subrurumỹ dè & ijasò & Peixe aruanã \\
\hline Nawiè & usehewe & Ema \\
\hline Hãrurure & hitxiõ & Pacu manteiga \\
\hline
\end{tabular}

- Xavante (Francisco Rodrigues Tsereneewe Tsipibu, Glicério Tseretuiwe Ruwa Adi e José Uratsé Aihe Edi, da Turma de 2013):

\begin{tabular}{|l|l|l|}
\hline Palavras Antigas & Palavras Atuais & Português \\
\hline 'ramẽ & $a m \tilde{e}$ & Mamãe \\
\hline ' $u$ & $\ddot{o}$ & Água \\
\hline$\tilde{\iota}^{\prime} r a d a$ & $\tilde{\iota} d a$ & Avó, avô \\
\hline tsai'uri & atsai'uri & Subir \\
\hline
\end{tabular}


c) Empréstimos do Português e Formação de novas palavras nas línguas indígenas:

- Tapirapé (Iranildo Arowaxeo’i Tapirapé, da Turma de 2009):

\begin{tabular}{|l|l|}
\hline Kojapa'axiga & 'bola' (kojapa'a 'cuia' + xiga 'branca') \\
\hline Mexo'i & $\begin{array}{l}\text { 'bolacha' (mexo 'beiju' + i 'morfema de } \\
\text { diminutivo') }\end{array}$ \\
\hline Xixinyãra & 'avião' (xixina 'libélula' + yãra 'transporte') \\
\hline O’ypepakyxiãwa & $\begin{array}{l}\text { 'tesoura' (o'y 'flecha' + pepa 'asa' + kyxi 'cor- } \\
\text { tar' + ãwa 'morfema nominalizador') }\end{array}$ \\
\hline
\end{tabular}
de 2010):

- Apinajé (Emílio Dias e Gilberto Pereira Apinajé, da Turma

\begin{tabular}{|l|l|}
\hline Pàrprõt & 'carro' (pàr 'tronco' + prõt 'que corre') \\
\hline Pàrjara & 'avião' (pàr 'tronco' + jara 'asa') \\
\hline Pàrtôore & 'patrola' (pàr 'tronco' + tôore 'que cola, gruda') \\
\hline Kupekarõ & televisão' (kupe 'não indígena' + karõ 'imagem') \\
\hline Kàxkaper & 'rádio' (kàx 'ferro' + kaper 'falar') \\
\hline
\end{tabular}

d) Palavras distintas entre idades/gerações:

- Karajá (Labé Kalariki Idjawaru Karajá, Lahyre Karajá, Moisés Waixa Karajá, Nelson Wanahuwa Karajá e Txiixe Iòló Tapirapé):

\begin{tabular}{|l|l|l|}
\hline Fala dos Anciãos & Fala dos Jovens & Tradução \\
\hline Òhura & wdena & Arpão \\
\hline Hty & rnysityby & Lixo \\
\hline Brèò & hetoriòre & Casinha \\
\hline Irusarusa & irui & Mentiroso \\
\hline Tatyryò & tahewoò & Para trás (atrás) \\
\hline
\end{tabular}


- Xavante (Francisco Rodrigues Tsereneewe Tsipibu, Glicério Tseretuiwe Ruwa Adi e José Uratsé Aihe Edi, da Turma de 2013):

\begin{tabular}{|c|c|c|}
\hline Fala dos adultos & Infância & Português \\
\hline Tsinhốra & wanhõra & Finado primo, sobrinho \\
\hline Datiö & 'ramẽ & Mamãe (para meninos) \\
\hline Datiö & anapté & Tia \\
\hline
\end{tabular}

e) Palavras distintas entre os sexos:

- Xavante (Francisco Rodrigues Tsereneewetsipibu, Glicério Tseretuiwe Ruwa Adi, José Uratse Aihe Edi e Romano Tsorodadze Tserenhe Omo, da Turma de 2013):

\begin{tabular}{|l|l|l|}
\hline Fala dos Homens & Fala das Mulheres & Tradução \\
\hline Maredi & madzedi & Negação \\
\hline Té ruarĩ & Té tiha & De nada \\
\hline Prá & Pe & Admiração, espanto \\
\hline E'marĩ & E'tiha & O que? \\
\hline Anã & aimãmã & Cunhado (a) \\
\hline
\end{tabular}

f) Palavras distintas conforme as aldeias e regiões:

- Xavante: Há pelo menos duas palavras distintas, usadas nas diversas aldeias (Francisco Rodrigues Tsereneewe Tsipibu, Glicério Tseretuiwe Ruwa Adi e José Uratsé Aihe Edi, da Turma de 2013):

\begin{tabular}{|c|}
\hline 'carro': robduri ('coisa' + 'carregar'), wedewara ('árvore' + 'correr') \\
\hline $\begin{array}{l}\text { 'bicicleta': robduridza'e ('carro' + 'fino'), tsi'uwadziwara ('ferro' + } \\
\text { 'andante') }\end{array}$ \\
\hline $\begin{array}{l}\text { 'vaca, gado': podzewatsde ('gado' + 'mau, ruim'), powawẽ ('gado' } \\
+ \text { 'grande') }\end{array}$ \\
\hline 'açúcar': adze ('algo doce'), tsuparare ('areia') \\
\hline
\end{tabular}




\section{AS DISCUSSÕES REALIZADAS SOBRE CAMPOS LEXICAIS}

Os alunos das turmas de 2007 e 2008 escreveram textos bilíngues em suas línguas indígenas e em português, sobre o Campo Lexical "aves", como se segue, tendo por base o texto de Seki (2008). Após amplas discussões, eles decidiram que seus textos abrangeriam informações sobre os tipos de aves existentes, seu tamanho e demais características físicas, hábitos, hábitat, alimentação, reprodução, função social das aves e mitos a elas relacionados.

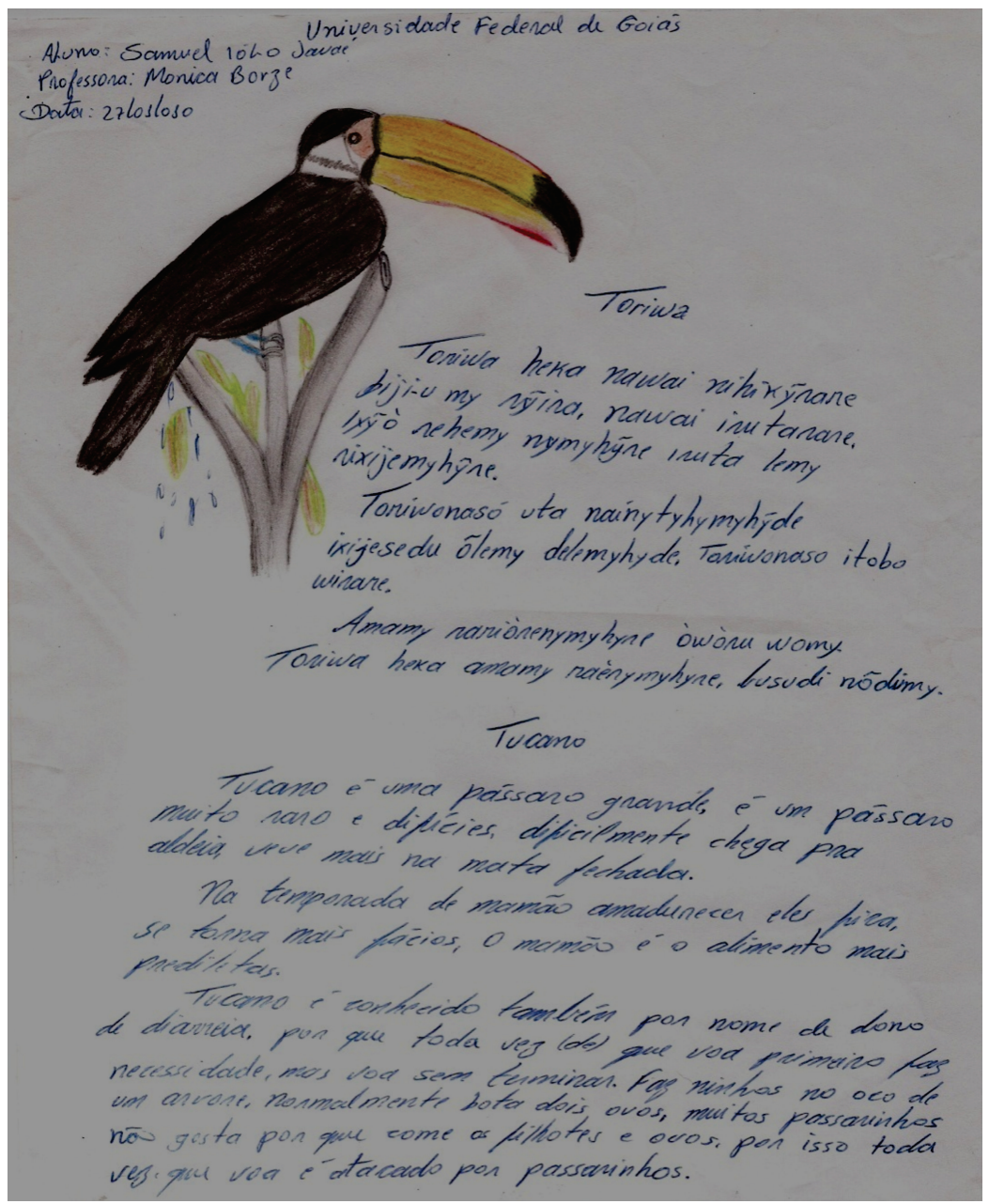

Texto escrito sobre o toriwa (tucano) pelo Professor Samuel Iòlò Javaé, da Turma 
de 2008, nas línguas Javaé e portuguesa.

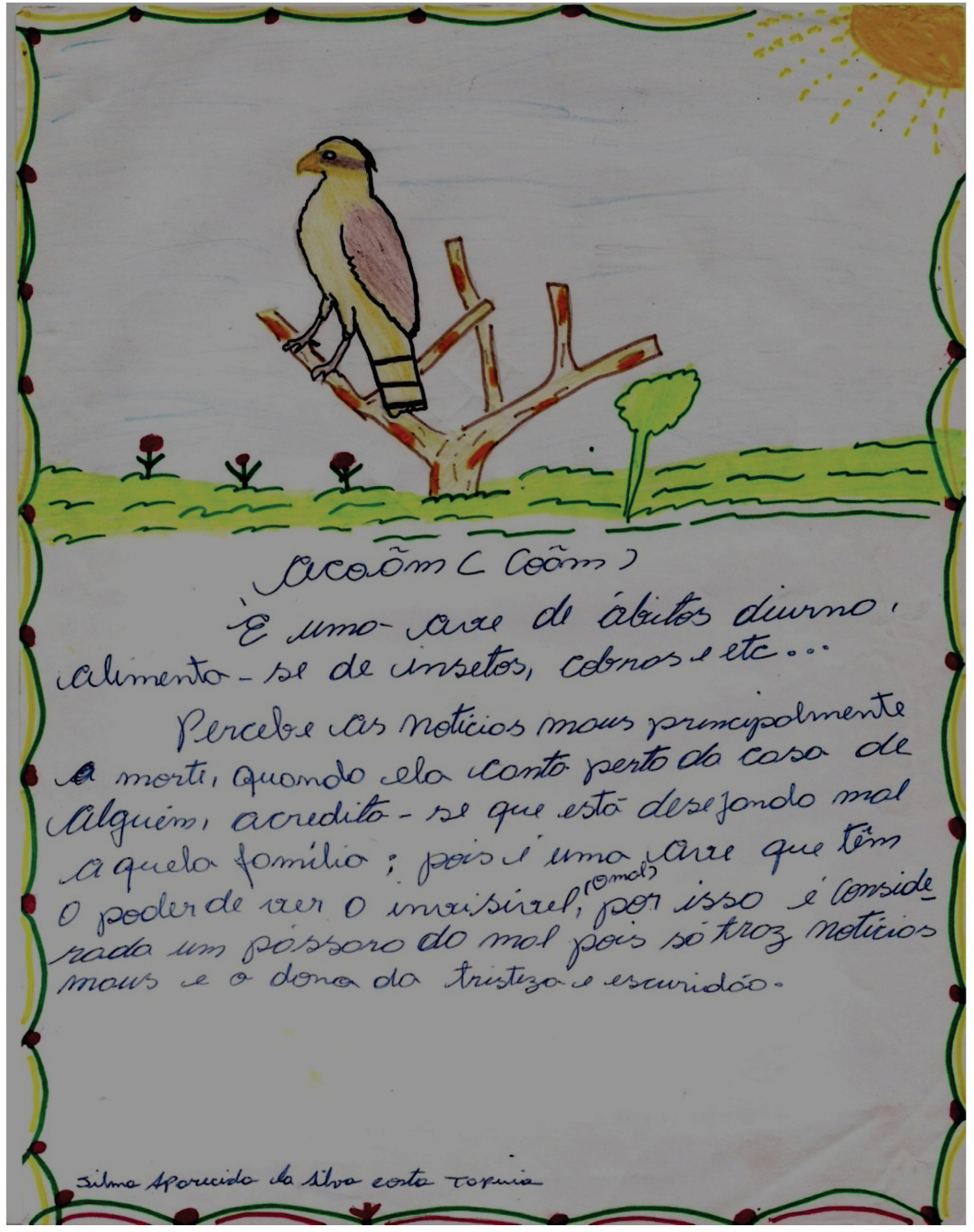

Texto escrito sobre a acoãm/coãm (coruja) pela Professora Silma Aparecida da Silva Costa Tapuia, da Turma de 2007. 


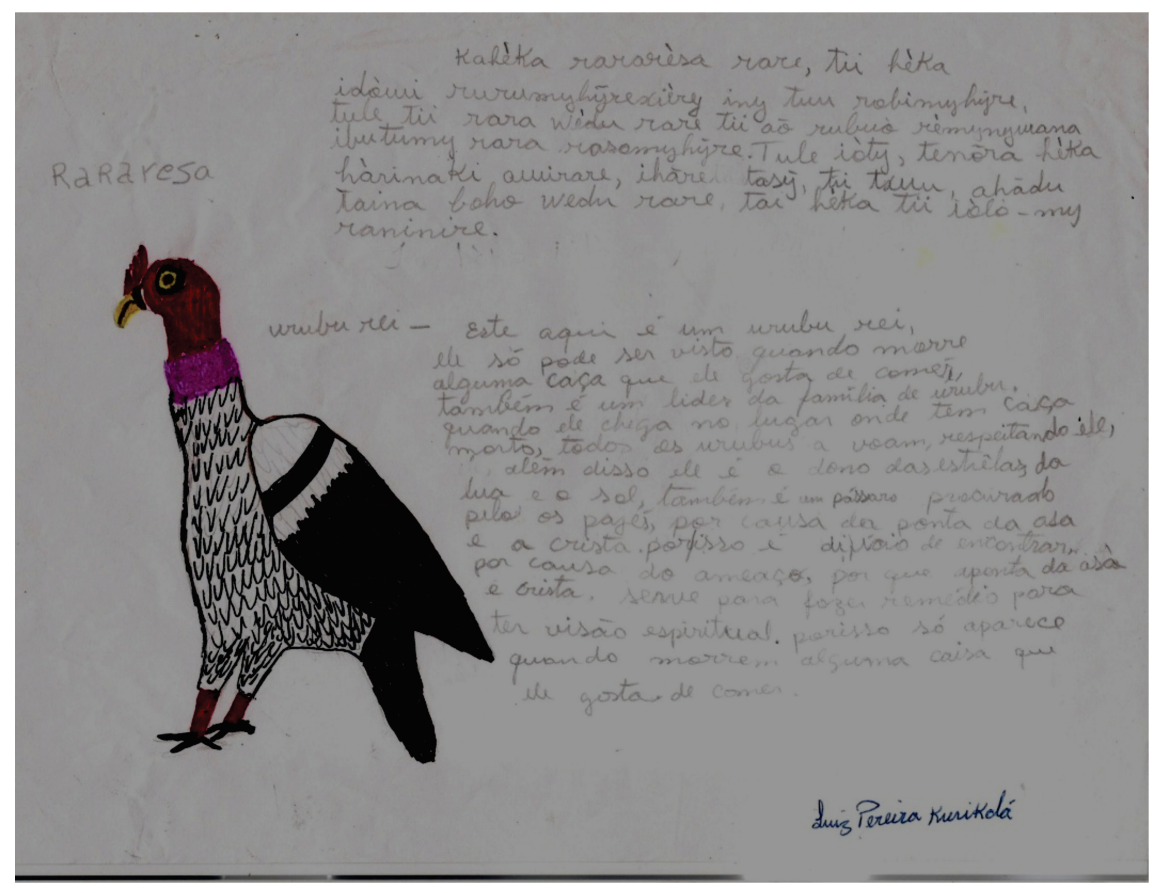

Texto escrito sobre o raresa (urubu-rei) pelo Professor Luiz Pereira Kurikalá Karajá, da Turma de 2007, nas línguas Iny (Karajá) e portuguesa.

Com as turmas de 2009 e 2010, cada grupo de alunos, por povo, escolheu um dos campos lexicais a seguir, para desenvolver suas pesquisas, conforme se segue. As discussões foram realizadas em grupos, e os textos e os desenhos foram produzidos de forma individual ou coletiva, de acordo com a decisão de cada um.

\section{Povo Tapirapé: Campo Lexical "Peixes" - Discussões} realizadas: tipos de peixes, local onde sãos encontrados, tipos de preparo e de consumo, comércio, saúde, pescarias, pescarias e pajé. Os alunos decidiram que os textos seriam escritos apenas em língua Apyãwa (Tapirapé). 


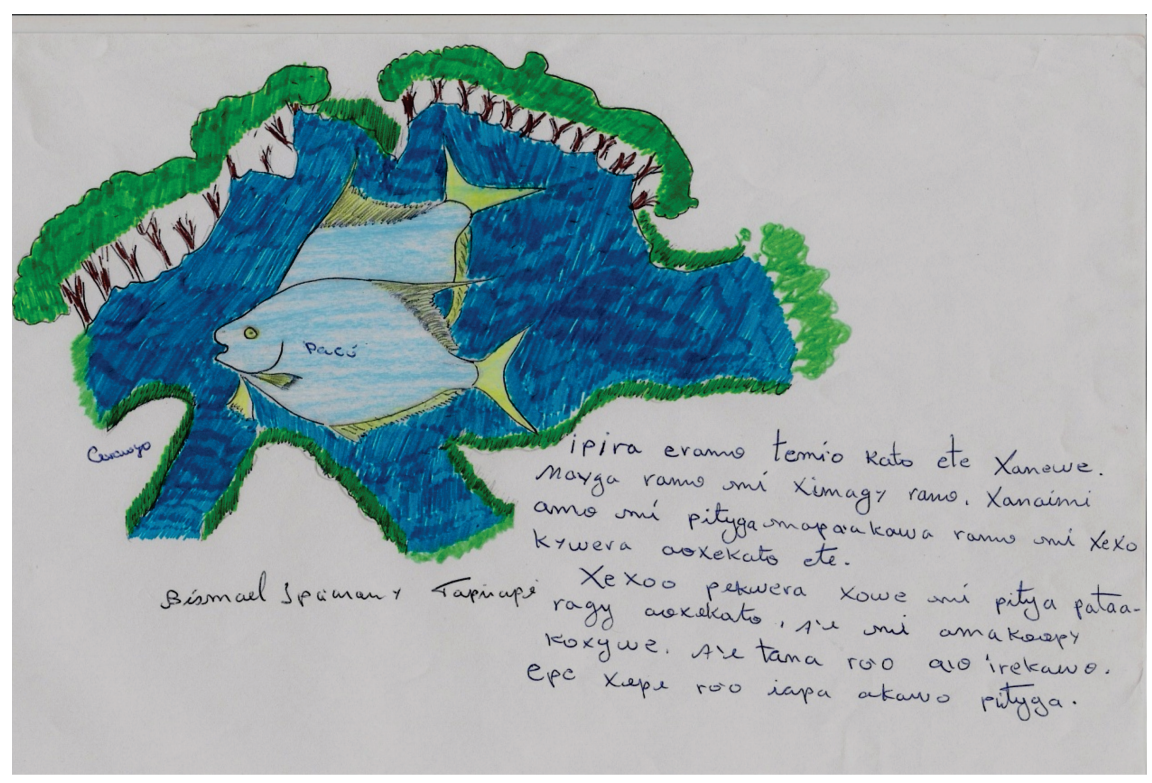

Texto sobre ipira (peixes), escrito pelo Professor Bismael Ipa’aramy Tapirapé, da Turma de 2010.

Povo Guajajara: Campo Lexical “Peixes/Rio" - Discussões realizadas: tipos de peixes, os tipos de peixes que há em cada rio, tipos de peixes que podem ou não ser consumidos, peixes reimosos, restrições alimentares, cosmologia relacionada aos peixes, a importância dos rios. Os alunos decidiram que os textos seriam escritos somente em língua Guajajara. 


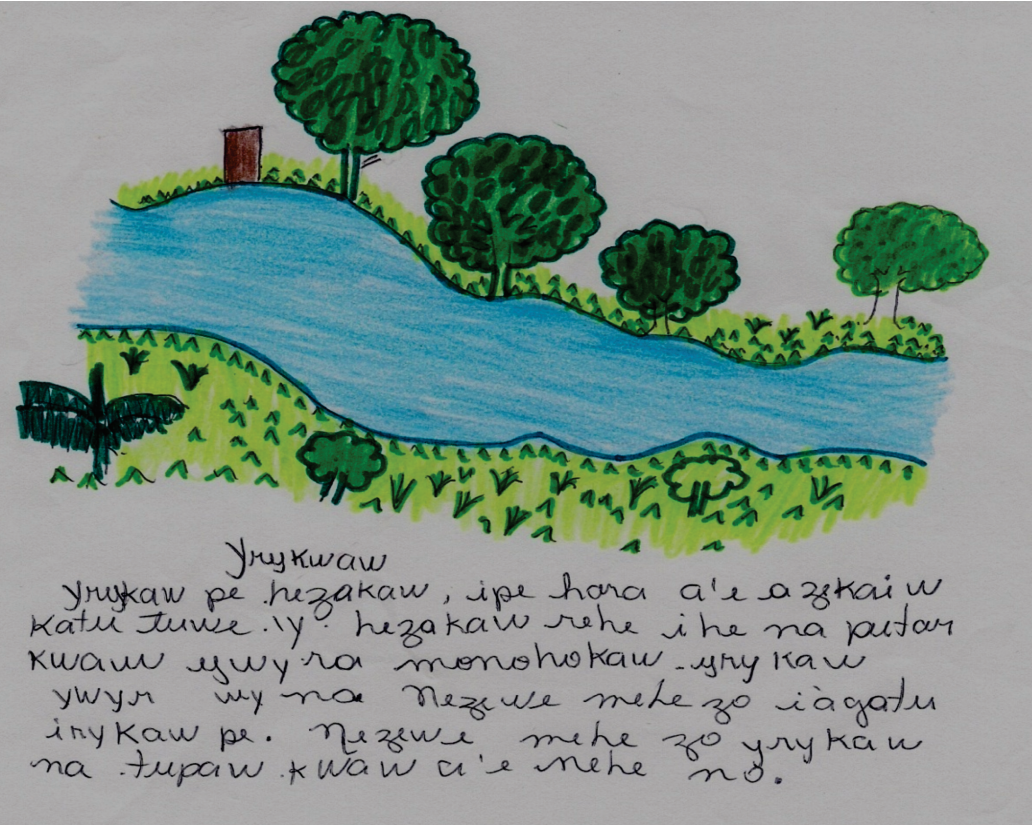

Texto escrito pela Professora Joeme Providências Gomes Guajajara, da Turma de 2010.

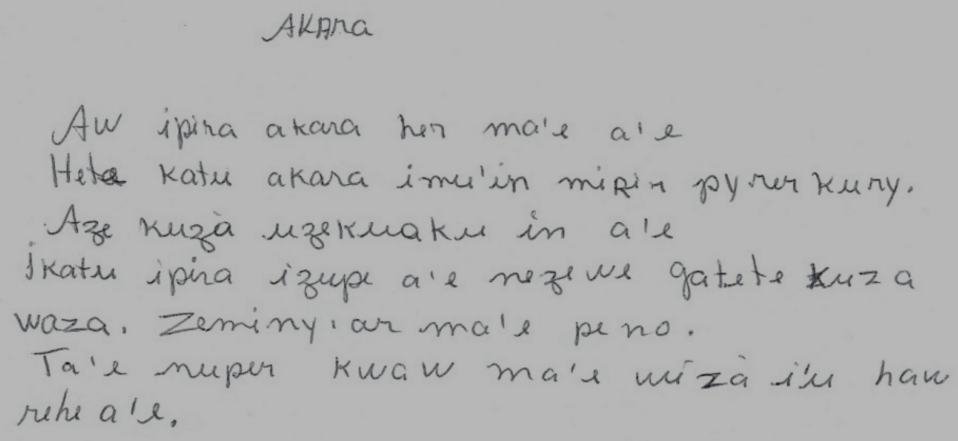

Texto escrito pelas Professoras Cíntia Maria Santana da Silva e Marina Cíntia da Silva Guajajara, da Turma de 2010. 


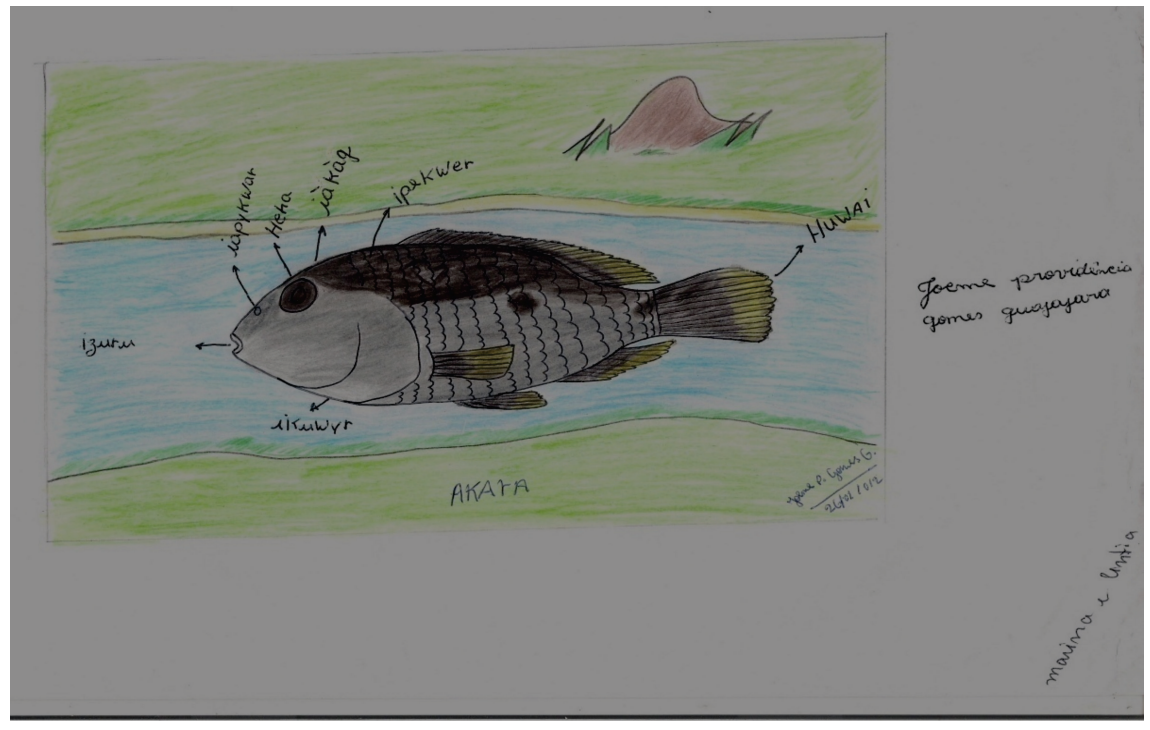

Desenho feito pela Professora Joeme Providências Gomes Guajajara, para ilustrar o texto escrito pelas Professoras Cíntia Maria Santana da Silva e Marina Cíntia da Silva Guajajara, da Turma de 2010.

Povo Xerente: Campo Lexical “Árvores" - Discussões realizadas: tipos de árvores, tamanhos das árvores, jatobá, três tipos de jatobá, lugar onde estão as árvores, artesanatos feitos com árvores como matéria-prima, as árvores que servem de remédio, de alimento, e para fornecer madeira para se construir casa e canoa. Os alunos optaram por escrever seus textos em língua Akwẽ (Xerente), exclusivamente. 


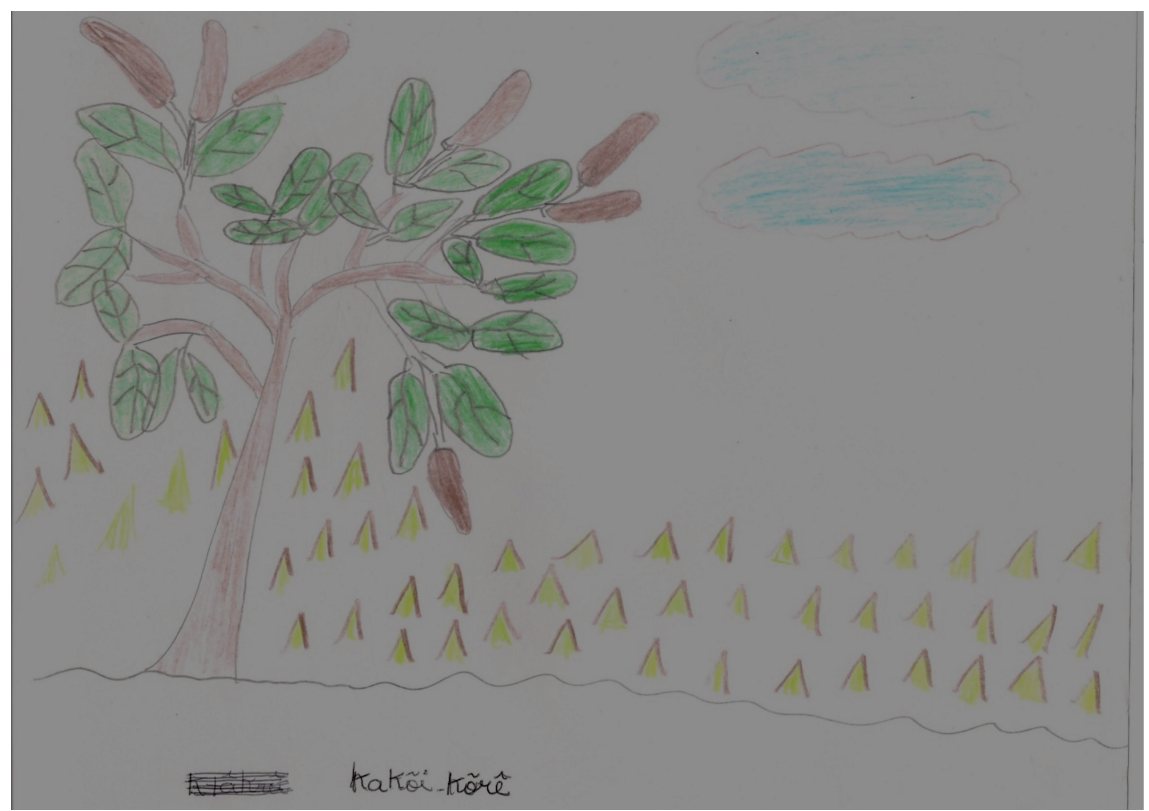

Desenho feito pela Professora Helena Krukwane Xerente, da Turma de 2010.

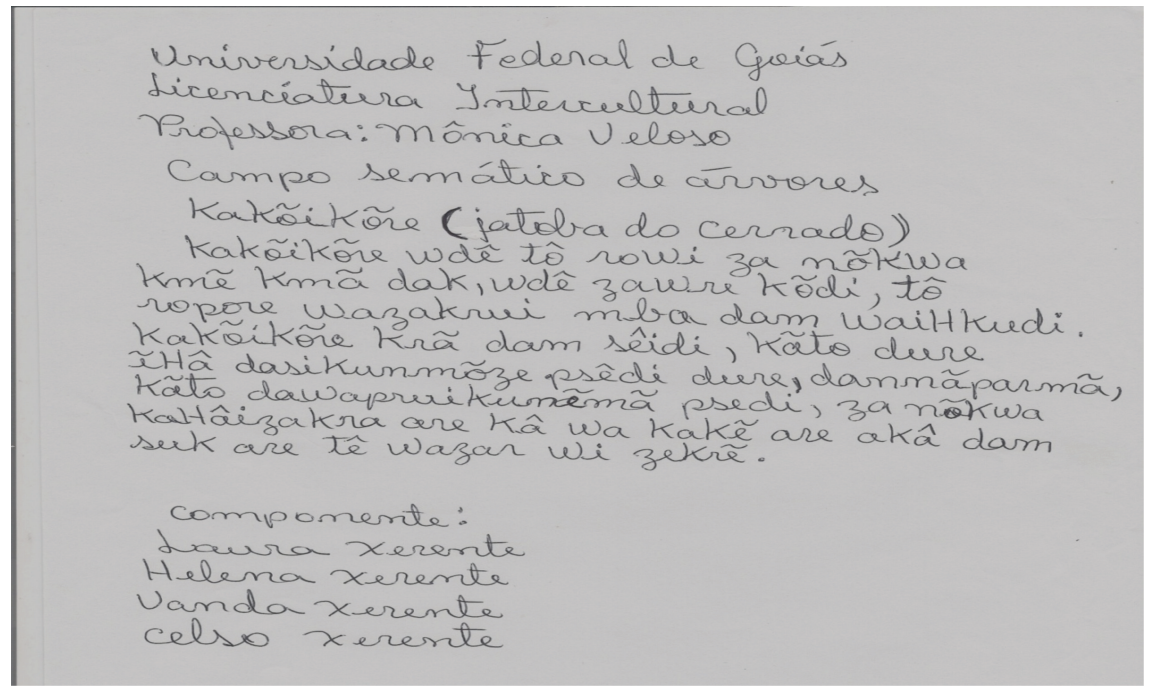

Texto escrito pelos Professores Laura Stukrepre Xerente, Helena Krukwane Xerente, Vanda da Mata de Brito Xerente e Celso Kazamre Xerente, da Turma de 2010. 


\section{Povos Gavião, Krahô, Apinajé, Krikati: Campo Lexical}

"Artesanato" - Discussões realizadas: tipos de artesanatos, matérias primas usadas na confecção dos diversos tipos de artesanato, lugar onde se coletam as matérias primas, processamento das matérias primas, utilização de cada tipo de artesanato, quem faz e utiliza cada tipo de artesanato, para que servem os artesanatos. Os alunos desses povos optaram por redigir seus textos apenas em suas línguas indígenas.

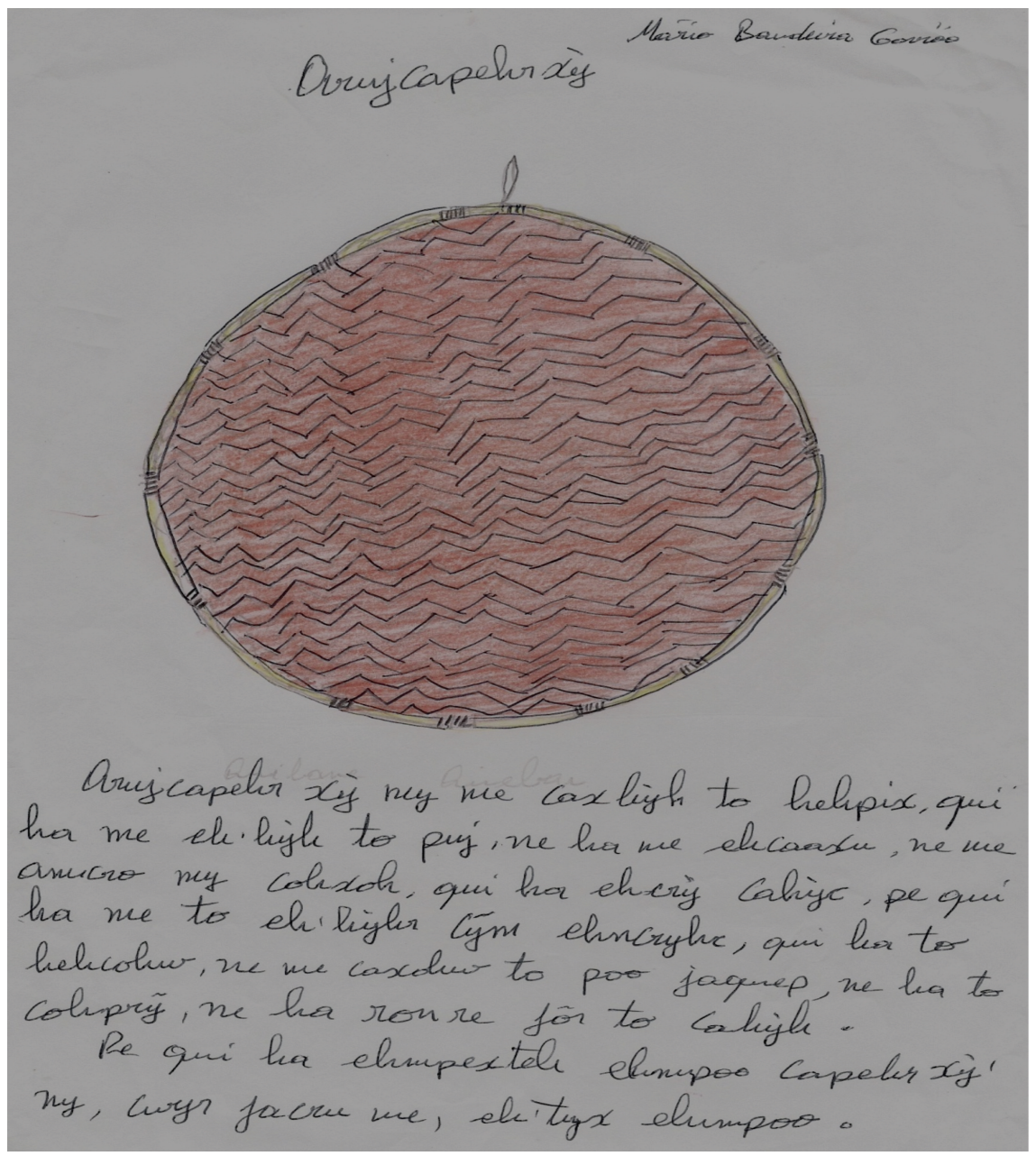

Texto escrito pelo Professor Mário Bandeira Gavião, da Turma de 2010. 


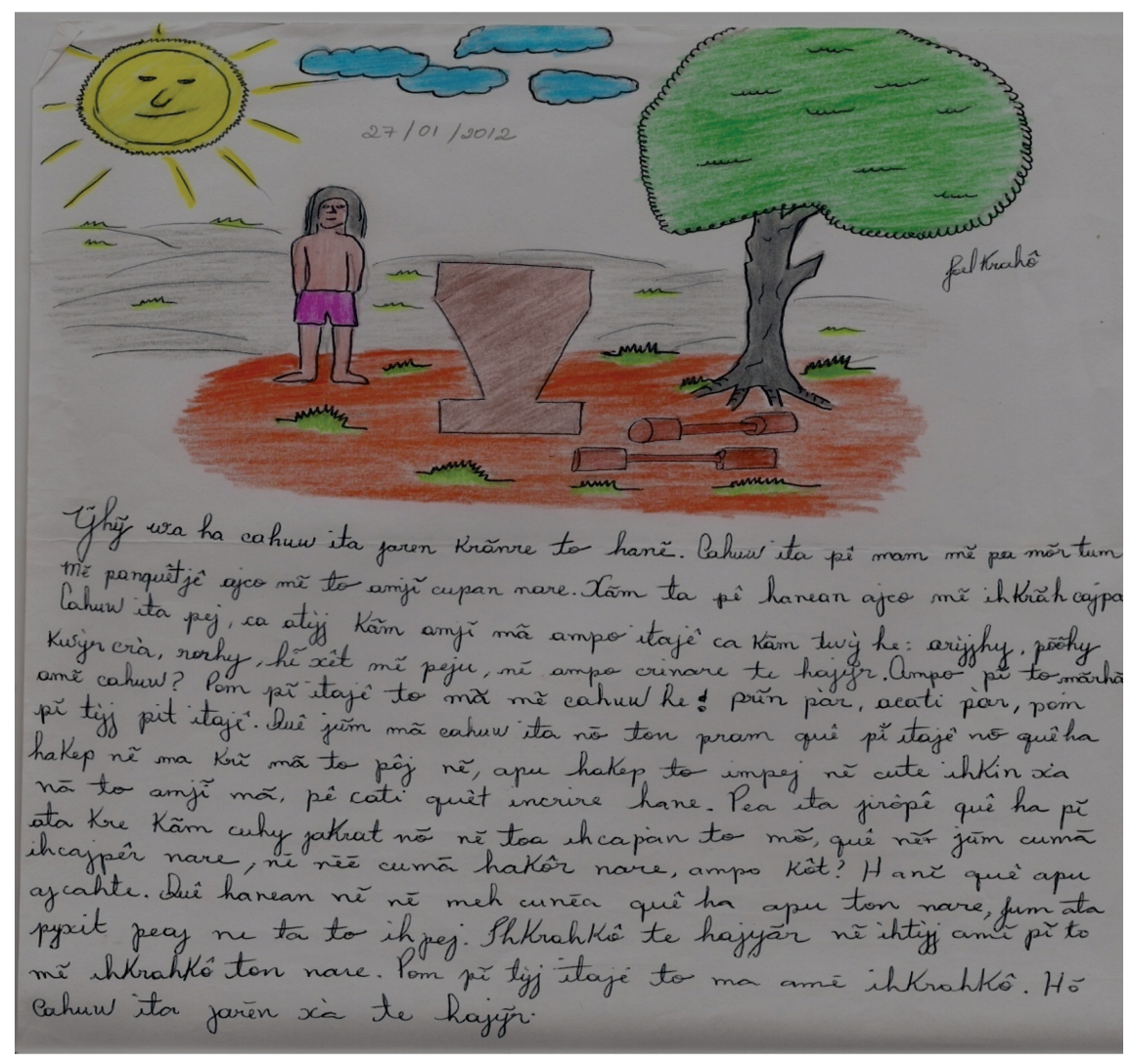

Texto escrito pelo Professor Joel Marcos Cuxy Krahô, da Turma de 2010.

Por último foi escolhido o Campo Lexical "Mito", que foi trabalhado pelas turmas de 2009, 2010 e 2011. Os alunos desenvolveram as seguintes discussões: história, origem, crenças, natureza, tradições, narrador, personagem, linguagem oral, ouvinte, espíritos, animais, pessoas, natureza, conhecimento, sabedoria, experiência, velhos, viagem, evento, texto, música, identidade, cultura, significado, especialistas, inteligentes, esperança, lugar, vivo, cosmologia, pajé, dança, pintura, costume, conhecimento para sempre, tempo passado, pessoa mais velha, direito, atenção, suspense, história de cada povo, religião, crença de cada povo indígena, festa cultural, aves, paz, amor, crianças, esteira, escola, professor, árvore, valorização, lua, ancião, família, fogo. Ao final, os alunos ficaram de pesquisar em suas aldeias os mitos mais relevantes e documentá-los em forma de 
desenhos e textos escritos em suas línguas indígenas.

Das Turmas de 2012 e 2013, cada povo trabalhou dois Campos Lexicais, quais sejam: 1) Xavante: frutas e peixes; 2) Javaé: casa e roça; 3) Xerente e Xakriabá: aves e plantas medicinais; 4) Karajá: animais e peixes; 5) Canela: roça e animais; e 6) Krikati: frutas e roça.

Os textos elaborados contemplaram os seguintes aspectos, selecionados pelos alunos, após discussões: 1) Peixes: nome, tipo de rio, características (cor, tamanho, couro/escama?), alimentação, se serve de alimento para o povo, lugar onde vive, reprodução, utilidade, mito relacionado?; 2) Aves: nome, alimentação, características, onde vive, se serve de alimento, se voa, ninhos, reprodução, utilidade, mito relacionado?; 3) Animais: nome, características, alimentação, onde vive, se serve de alimento, reprodução, utilidade, mito relacionado?; 4) Roça: o que se planta, tipo, calendário, coletiva/individual, divisão de trabalho, material usado, ritual, mito relacionado?; 5) Casa: como se constroe, materiais usados, características e tipos, época de construção, tipo de madeira, mitos relacionados?, atividades feitas na casa, onde é feita, quem constroe, onde se constroe, distância entre as casas; 6) Frutas: nome, tipos, características, utilidade, remédio?, onde se encontra, tipos de árvores, época (plantio, colheita), se planta, onde se planta, se colhe, mito relacionado?; 7) Plantas Medicinais: utilidade, nome, doença para que serve, como se prepara, como se usa, quem pode fazer o remédio, quem usa, lugar, características, parte usada, tempo de preparo, mito relacionado?, quem pode pegar/ conhecer a planta ou não.

\section{REFLEXÕES DOS ALUNOS SOBRE O TEMA CONTEXTUAL}

Ao término das atividades desenvolvidas, os alunos escreveram textos de avaliação sobre o Tema Contextual e sobre as discussões feitas, chegando, inclusive a algumas definições sobre léxico, seu estudo e sua documentação, apresentadas abaixo.

"O estudo do léxico envolve e abrange a leitura do mundo e a leitura da palavra” (Gilson Ipaxiławga Tapirapé, da Turma de 2007).

"Estudar o léxico significa o fortalecimento e a valorização da 
língua e de seu povo" (Gilson Ipaxi’awga Tapirapé, da Turma de 2007).

"O léxico é uma espécie de caixinha onde guardamos os nossos pertences e os de nosso povo" (Mário Bandeira Gavião, da Turma de 2010).

"O léxico é o lugar onde guardamos os nossos valores e os nossos conhecimentos para o presente e para sempre" (Bismael Ipaaramy Tapirapé, da Turma de 2010).

"O léxico está sempre com as portas abertas. Algumas palavras estão entrando, mas outras vão saindo" (Armando Sõpre Xerente, da Turma de 2011)

"Falar sobre a palavra especializada é muito diferente de usar essa palavra num contexto, a palavra contextualizada" (Adeilda Katoaxowa Tapirapé, Klebson Awararawooi Tapirapé e Waraxowooi Maurício Tapirapé, da Turma de 2011).

A conclusão a que os alunos chegaram foi que documentar e estudar o léxico é muito importante, porque, segundo eles, trata-se do "armazenamento do nosso conhecimento, nosso estoque mental das palavras, nosso léxico mental, nossa caixinha de conhecimento, nossa biblioteca mental". Desse modo, espero que os saberes aqui trazidos possam contribuir para que os professores indígenas dediquem-se à pesquisa, à documentação e ao ensino do léxico de suas línguas maternas em suas comunidades.

\section{REFERÊNCIAS}

ILARI, Rodolfo. Introdução ao estudo do léxico - brincando com as palavras. São Paulo: Contexto, 2002.

SEKI, Lucy. "Nomes de aves em Kamaiurá: aspectos linguísticos e extralinguísticos". MESSINEO, C.; MALVESTITTI, M.; BEIN, R. (Eds.). Estúdios en Lingüistica y Antropología. Homenaje a Ana Gersenstein. Buenos Aires: Facultad de Filosofia y Letras/Universidad de Buenos Aires, 2008. 299-311pp. 